\title{
ESTIMATIVA DE PERDA DE SOLO NO BAIXO SÃO FRANCISCO SERGIPANO
}

\author{
Prediction of soil loss in the lower são francisco river in sergipe state \\ Marks Melo Moura 1; Cátia dos Santos Fontes 2; Maria Hosana dos Santos 3; Renisson Neponuceno de Araujo \\ Filho ${ }^{4}$; Francisco Sandro Rodrigues Holanda ${ }^{5 *}$ \\ ${ }^{1}$ Engenheiro Florestal; Departamento de Engenharia Agronômica; Universidade Federal de Sergipe (UFS); e-mail \\ marksmoura@yahoo.com.br \\ ${ }_{2}^{2}$ Doutora em Geografia; Departamento de Engenharia Agronômica; Universidade Federal de Sergipe (UFS); e-mail \\ catiafjav@hotmail.com \\ ${ }^{3}$ Mestre em agricultura e biodiversidade; Departamento de Engenharia Agronômica; Universidade Federal de Sergipe (UFS); e- \\ mail hosana_bio@hotmail.com \\ ${ }_{4}^{4}$ Pos Doutorando; Departamento de Energia Nuclear; Universidade Federal de Pernambuco (UFPE); e-mail \\ nepoaraujo@gmail.com \\ ${ }^{5}$ Professor Titular; Departamento de Engenharia Agronômica; Universidade Federal de Sergipe (UFS); e-mail \\ fholanda@infonet.com.br (*AUTOR PARA CORRESPONDÊNCIA)
}

Artigo enviado em 12/01/2017, aceito em 26/04/2017 e publicado em 07/07/2017.

RESUMO: A predição de eventos erosivos é de grande importância nas terras do Baixo São Francisco-BSF, que apresentapráticas de manejo inadequado vem provocando degradação das áreas cultivadas e matas ciliares com consequente avanço de processos erosivos nas margens do rio. A Equação Universal de Perda de Solos (EUPS) é um modelo queutiliza dados pluviométricos, tipos de solos, declividade do terreno e uso do solo, para estimar a quantidade de solo perdida em uma determinada área. O objetivo desse trabalho foi estimar e avaliar as perdas de solo no Baixo São Francisco sergipano. O BSF ocupa uma área de 3.201 .300 ha, se iniciando em Paulo Afonso-BA, com sua foz entre Piaçabuçu-AL e Brejo Grande-SE. O trecho no estado de Sergipe ocupa uma área de 738.754ha, onde foi estimada a perda de solos. Nas áreas de pastagem, que ocupam $76 \%$ do BSF, foram encontrados valores que variaram de 0 a $0,33 \mathrm{t} \mathrm{ha}^{-1}$ ano $^{-1}$ de perda de solo. Somente $0,1 \%$ da área estudada apresentou alto risco de erosão, justificado pela predominância de áreas com ocorrência de baixa erosividade, associada à uma cobertura do solo mais conservacionista como as pastagens. A baixa expressividade das perdas de solo se mostra resultante da combinação de vários fatores, com ênfase na baixa erosividade.

Palavras-Chave - Erosão, EUPS, SIG

Abstract - The prediction of erosive events have this great importance in the lands of lower São Francisco-LSF, where
practices of inadequate management have led to degradation of cultivated areas and riparian forests, with consequent
advance of erosive processes along the river banks. The Universal Soil Loss Equation (USLE) is a model that uses
pluviometric data, soil types, land slope and land use, to calculate how much soil loss in a given area in a year. The
objective of this work was to estimate and to evaluate the soil losses in the Lower São Francisco of Sergipe state. The
LSF occupies an area of 3,201,300 ha, from Paulo Afonso-BA, to the mouth of the river between Piaçabuçu-AL and
Brejo Grande-SE. The stretch in the state of Sergipe occupies an area around 738.754 ha, where soil loss was calculated
using ArcGis 9.0 software. The pasture areas are predominant in the Basin, occupying more than half of the LSF
( $76.26 \%$ ), values ranging from 0 to 0.33 tha- 1 year -1 of soil loss. Only $0.1 \%$ of the studied area presented a high risk
of erosion, justified by the predominance of areas with low erosivity, associated to a more conservationist soil cover
mostly by pastures.The low expressiveness of soil losses is shown by the combination of several factors, with emphasis
on low erosivity. Keywords - Erosion, USLE, GIS 


\section{INTRODUÇÃO}

O solo é um recurso importante não só como suporte para culturas agrícolas eflorestas, mas também promove de maneira direta ou indireta a manutenção do equilíbrio biológico e ecológico de determinada área ou região. Ações antrópicas ou naturais podem afetar negativamente este recurso, uma delas é a erosão que ocorre em três fases, a desagregação do solo,o transporte desse material efetuado pelos agentes erosivos e a terceira fasecorresponde a deposição do material transportado, só ocorrendo na ausência deenergia suficiente para dar continuidade ao transporte (GUERRA, 1994). Nas regiões tropicais,o principal fatorerosivo são as precipitações pluviométricas, pois concentram grandes volumes, com eventos de alta intensidade,sazonalidade, potencializando seu poder erosivo (GUERRA et al. 2017).

As consequências dos processos erosivos são numerosas e destacam-se a curto prazoem perdas de solos férteis e seu impacto na agricultura,e a longo prazo no assoreamento dos cursos d'água ou reservatórios (ISSA et al., 2014). Segundo Magyari-Sáska (2008) o processo de erosão do solo produz efeitos nocivos em um tempo relativamente curto em relação ao tempo de recuperação, sendo assim muito importante identificar as vulnerabilidades, para a implementação de medidas preventivas.

Existem vários métodos para estimar a erosão hídrica do solo (WEPP, PISA, SHETRAN, USLE, etc.). Alguns deles estudam a erosão em canais de escoamento, enquanto outros na totalidade da superfície (VIECELI et al., 2015). Um dos métodos mais frequentemente utilizados é a Equação Universal de Perdas de Solo (EUPS) (WISCHMEIER \& SMITH,1978), e as outras versões delas. A EUPS é um modelo empírico muito utilizado em planejamentos conservacionistas, pela sua simplicidade e facilidade naaquisição dos dados.

Vários fatores influenciam nos processos erosivos, sendo os fatores topográficos declividade e comprimento de rampa, os índices de precipitação, a cobertura vegetal e a erodibilidade do solo, os principais fatores. Segundo Magyari-Sáska (2008) a EUPS utiliza estes fatores para estimativa de perda de solo em determinada área, onde a mensuração dos processos erosivos é dificultada pelo tamanho da área, sendo inviável sua mensuração manual. Outro fator primordial são as alterações hidrológicas causadas pela sucessão de barragens, utilizadas para geração de energia, que regulam a vazão, diminuindo ou aumentando de acordo com os níveis do reservatório. Segundo Aguiar Netto; Costa e Oliveira (2016)a regulação da vazão causa consequências econômicas para a população ribeirinha e para a economia sergipana, sobretudo por acarretar problemas sociais, dentre os quais, os relacionados à pesca, à erosão marginal e causando prejuízos até mesmo nos perímetros irrigados, com perda de terras agricultáveis.
Segundo Kumar; Devi e Deshmukh(2014) a magnitude da erosão superficial e produção de sedimentos variam espacialmente em uma bacia hidrográfica, devido às variações das chuvas e heterogeneidade das áreas de captação. Desenvolvimentos recentes em Sensoriamento Remoto e Sistemas de Informações Geográficas (SIG) têm aperfeiçoado a capacidade de lidar com grande número e heterogeneidade de dados que descrevem a superfície da área ou região estudada. Juntas essas ferramentas tem fornecido meios para identificar os fatores físicos que controlam o processo de erosão do solo e saída de sedimentos de bacias hidrográficas (VALLADARES et al., 2012).

O Baixo São Francisco (BSF) teve seu fluxo hidrossedimentológico modificado pela construção de grandes reservatórios de água, utilizados para geração de energia, resultando na regularização da vazão, retenção de sedimentos nas barragens, redução nas descargas de sedimentos nos exutórios, controle de enchentes, degradação da vegetação ciliar, erosão marginal, recuo da margem e perda de área agricultável (ARAÚJO FILHO et al, 2013), esses elementos associados com as condições de relevo, condições climáticas e falta de planejamentos conservacionistas promovem a aceleração dos processos erosivos.

O objetivo desse trabalho foi estimar e avaliar as perdas de solo no Baixo São Francisco sergipano.

\section{MATERIAL E MÉTODOS}

\section{Caracterização da área de estudo}

A região do Baixo São Francisco encontra-se localizada entre as coordenadas geográficas de $8^{\circ}$ e $11^{\circ}$ de latitude sul e $36^{\circ}$ e $39^{\circ}$ de longitude oeste, constituindose na porção mais oriental da bacia, ocupando uma extensão territorial de $30.377 \mathrm{~km}^{2}$ (CBHSF, 2016).

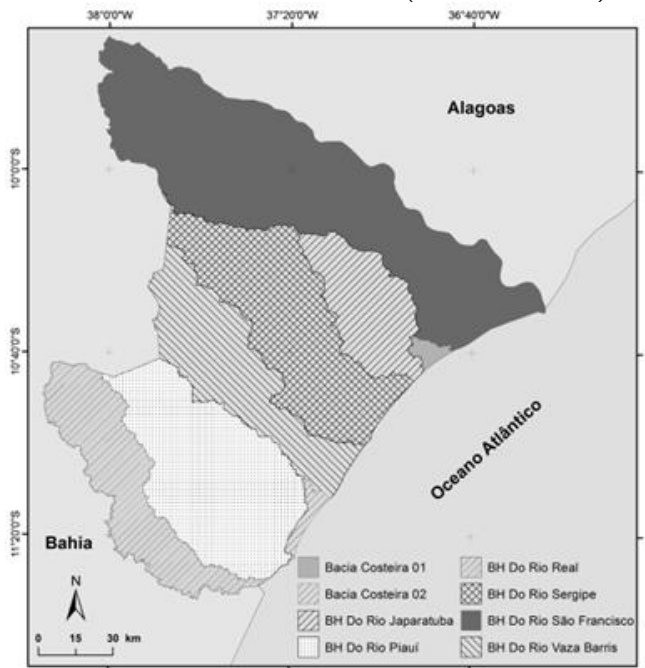

Figura 1- Localização do Baixo São Francisco sergipano (CBHSF, 2009). 
O Baixo São Francisco (BSF) corresponde a 5,1\% do total da área da Bacia Hidrográfica do Rio São Francisco e tem início em Paulo Afonso-BA, com sua foz no Oceano Atlântico entre Piaçabuçu-AL e Brejo Grande-SE. O Baixo São Francisco Sergipano abrange 738.754 ha o que corresponde à $1,2 \%$ da área da Bacia e inclui em sua área 28 municípios (SEPLAN, 2015).

No BSF as atividades antrópicas são bastante intensas, até como consequência histórica da ocupação territorial da faixa litorânea. $\mathrm{O}$ aumento da urbanização aliado com a falta de manejo e conservação dos solos é um agravante na condição atual das margens do Rio São Francisco Sergipano.

Quanto a geologia predominam no Baixo São Francisco os terrenos do Neoproterozóico (46\%) que pertence a unidade mais representativa da região com presença de xistos aluminosos, micaxistos, quartzitos, metagrauvaques, metarritmitos e rochas calciclásticas. As principais unidades geológicas aflorantes são do complexo Belém do São Francisco (16\%), Macurué $(13 \%)$ e Grupo Barreiras (8\%) (CPRM, 2003). A Geomorfologia da área é caracterizada pela ocorrência, de leste para oeste, de três Domínios morfoestruturais em três unidades geomorfológicas: Depósitos sedimentares e estende-se por áreas marginais do Rio São Francisco e pelos litorais dos estados de Sergipe e Alagoas; Remanescentes das Raízes de Dobramentos, situado na porção central do Baixo São Francisco, aproximadamente entre as cidades de Porto da Folha e Propriá (SE); Maciços Remobilizados que ocupam a maior área do Baixo São Francisco, estendendo-se de Porto da Folha até Paulo Afonso (CODEVASF, 2002).

Segundo os dados da Infraestrutura Nacional de Dados Espaciais (INDE, 2014) as principais unidades de relevo no Baixo São Francisco são: depressões do Baixo São Francisco (59\%), Tabuleiros dos rios Real/VazaBarris $(18 \%)$, Planalto da Borborema $(8 \%)$, Tabuleiros Costeiros (8\%), Planícies Marinhas (3\%), Tabuleiros de Tonã/Jatobá (2\%) e corpos de águas (3\%) (ANA/GEF/PNUMA/OEA, 2015).

No Baixo São Francisco, os tipos de solos com maior representatividade são os Planossolos (41,5\%), os Neossolos (32,5\%) e os Argissolos (13,3\%) (EMBRAPA, 2013).

A parte sedimentar do Baixo São Francisco segundo a classificação de Köppené Am (Megathermic húmido e subhumid), com temperatura média anual de $25^{\circ} \mathrm{C}$, sendo dezembro o mês mais quente $\left(26-27^{\circ} \mathrm{C}\right)$ e Junho o mês mais frio (cerca de $23{ }^{\circ} \mathrm{C}$ ). No trecho cristalino émegatérmico semi-árido brando, com temperatura média anualde $26^{\circ} \mathrm{C}$ e período chuvoso compreendendo os meses demarço a agosto, com precipitação média anual de $806,1 \mathrm{~mm} /$ ano (SEPLAN, 2007).

\section{Aplicação da EUPS - Equação Universal de Perda de Solo}

$\mathrm{Na}$ área em estudo foi estimada a perda de solos utilizando o software ArcGis 9.0 como ferramenta para entrada e análise dos dados.Apesar de suas limitações a EUPS continuasofrendo atualizações emodificações, sendo um valioso instrumento para a conservação do solo (BERTONI e LOMBARDI NETO, 1990). A EquaçãoUniversal de Perda de Solo é dada pela expressão:

$$
\mathrm{A}=\mathrm{R} \times \mathrm{K} \times \mathrm{LS} \times \mathrm{C} \times \mathrm{P} \text { Eq.1 }
$$

Onde: $\mathrm{A}=$ perdas desolo $(\mathrm{t} /$ ha.ano $) ; \mathrm{R}=$ erosividadedas chuvas (MJ/ha).(mm/h); K = Erodibilidade do solo (t.ha.h /MJ.mm); LS = fator de declividade $\mathrm{e}$ comprimento da rampa (Adimensional); $\mathrm{C}=$ fator cobertura; e $\mathrm{P}=$ fator práticas conservacionistas (Adimensional).

\section{Cálculo do fator R - Erosividade}

Para este cálculo foi utilizada a Equação 2, proposta por SUDENE (1985) para a região Nordeste, utilizando como base o trabalho de Bertoni e Lombardi Neto (1990) para determinação de um valor médio do índice de erosividade por meio da relação entre a média mensal e a média anual de precipitação.

$$
\mathrm{EI}=89.823 \times\left(\frac{\mathrm{r}^{2}}{\mathrm{R}}\right)^{0,759} \mathrm{Eq} .2
$$

Onde: $\mathrm{EI}=$ média mensal do índice de erosividade (MJ.mm/ha/ h); r = média mensal de precipitação $(\mathrm{mm}) ; \mathrm{P}=$ média anual de precipitação $(\mathrm{mm})$.

Foram coletados dados entre os anos 1990 e 2013 em 13 estações pluviométricas, sendo 11 instaladas nos municípios sergipanos (Aquidabã, Brejo Grande, Canindé do São Francisco, Japaratuba, Monte Alegre, Neópolis, Pacatuba, Pirambu, Poço Redondo, Propriá e Porto da Folha), uma no município baiano de Paulo Afonso e outra em Penedo município d o estado de Alagoas. Inicialmente foi calculado o EI utilizando a Equação2. A partir do somatório do EI de todos os meses foi obtido o fator $\mathrm{R}$ para cada estação da bacia, como mostra a Equação 3.

$$
\mathrm{R}=\sum \mathrm{EI} \quad \mathrm{Eq} \cdot 3
$$

A classificação da erosividade foi orientada pela Tabela 1 utilizada por Carvalho (2008). 
Tabela 1 - Classificação da erosividade tomando como referência o fator R (CARVALHO, 2008).

\begin{tabular}{cc}
\hline Erosividade & $\begin{array}{c}\text { fator } \mathrm{R}(\mathrm{Mg} \cdot \mathrm{mm} / \\
\text { ha.h.ano })\end{array}$ \\
\hline Fraca & $\mathrm{R}<250$ \\
Moderada & $250<\mathrm{R}<500$ \\
Moderada a forte & $500<\mathrm{R}<750$ \\
Forte & $750<\mathrm{R}<1000$ \\
Muito forte & $\mathrm{R}>1000$ \\
\hline
\end{tabular}

Com os dados do fator $\mathrm{R}$ associados a cada estação, foi possível estimar esse fatorpara toda área, utilizandoo método da Krigagem da ferramenta GeostatisticalAnalyst, esse método permite criar superfícies a partir de medições de dados obtidos através da amostragem da erosividade nas estações.

\section{Cálculo do fator K - Erodibilidade}

Os dados dofator $\mathrm{K}$ foram obtidos através de revisão de literatura, na qual foi baseada no Levantamento Exploratório e Reconhecimento de solos do Estado de Sergipe com Escala 1:400.000. Após a atualização das nomenclaturas de acordo com o novo sistema de classificação de solos da EMBRAPA (2013), foram atribuídos os valores correspondentes para cada classe como demostrado na Tabela 2.

Tabela 2 - Fatores de Erodibilidade para cada classe solo.

\begin{tabular}{|c|c|c|}
\hline Classes de Solo & fator $K$ & Fonte \\
\hline $\begin{array}{c}\text { Argissolo Vermelho- } \\
\text { Amarelo }\end{array}$ & 0,004 & Silva et al., 2007 \\
\hline Espodossolo & 0,03 & $\begin{array}{l}\text { Mannigel et al., } \\
2002\end{array}$ \\
\hline Gleissolo & 0,038 & Silva et al., 2007 \\
\hline Luvissolo & 0,03 & Baptista, 1997 \\
\hline NeossoloFlúvico & 0,042 & Silva et al., 2007 \\
\hline NeossoloLitólico & 0,04 & Silva et al., 2007 \\
\hline NeossoloQuartzarênico & 0,032 & Silva, 2004 \\
\hline NeossoloRegolítico & 0,041 & Silva et al., 2007 \\
\hline Planossolo & 0,02025 & $\begin{array}{l}\text { Mannigel et al., } \\
2002\end{array}$ \\
\hline $\begin{array}{c}\text { Solos Indiscriminados } \\
\text { de Mangue }\end{array}$ & 0,07 & Pimenta, 1998 \\
\hline
\end{tabular}

Cálculo do fator LS - Declividade e Comprimento da Rampa

O fator LS foi calculado utilizando um Modelo Digital de Elevação (MDE) obtido através do mosaico de imagens Shuttle Radar Topography Mission (SRTM) do ano 2012 com resolução espacial de 30 metros. As imagens foram adquiridas gratuitamente no site do Serviço Geológico Americano (USGS, 2014). Inicialmente foi recortada a região estudada, o Baixo São Francisco.

Para o cálculo do fator LS utilizou-se a metodologia proposta pelo GIS Assessment Service, que obtêm os valores do fator comprimento de rampa (L) e em seguida relaciona com o mapa de declividade (fator S), através da Equação 4 (FAIRFIELD e LEYMARIE, 1991; MOORE e WILSON, 1992).

$$
L S=\left(\frac{C}{22,13}\right)^{0,6} \times\left(\frac{\operatorname{Sen}(D)}{0,09}\right)^{1,3} \text { Eq.4 }
$$

Onde: LS - fator Topográfico $\left(^{\circ}\right)$; C - Tamanho do Pixel (m); D - Declive $\left(^{\circ}\right)$.

\section{Cálculo do fator CP - Uso da terra e práticas conservacionistas}

Para obtenção do fator CP foi necessário verificar os usos do solo no BSF sergipano, e para isso utilizou-se dados de revisões bibliográficas e da Superintendência de Recursos Hídricos de Sergipe (SERGIPE, 2012). Para cada uso e ocupação do solo foi atribuído um valor de literatura obtido em trabalhos similares de perda de solo. Estes dados foram classificados e cada uso teve um valor CP específico para o uso do solo como mostra a Tabela 3.

Tabela 3 -Usos do solo da Bacia e seu respectivo Fator CP.

\begin{tabular}{|c|c|c|}
\hline Usos do Solo & $\begin{array}{c}\text { fator } \\
\text { CP }\end{array}$ & Fonte \\
\hline Área Degradada & 0,1 & $\begin{array}{l}\text { Paranhas Filho et } \\
\text { al.(2003) }\end{array}$ \\
\hline Área Embrejada & 0 & $\begin{array}{c}\text { Paranhas Filho et } \\
\text { al. (2003) }\end{array}$ \\
\hline Área Industrial & 0 & $\begin{array}{c}\text { Paranhas Filho et } \\
\text { al. (2003) }\end{array}$ \\
\hline Caatinga & 0,0167 & Santos et al. (2014) \\
\hline Corpos D’água & 0 & $\begin{array}{c}\text { Paranhas Filho } e t \\
\text { al. (2003) }\end{array}$ \\
\hline $\begin{array}{c}\text { Cultivos Agrícolas/ Solos } \\
\text { expostos }\end{array}$ & 1 & $\begin{array}{l}\text { Farinassoet al. } \\
\qquad(2006)\end{array}$ \\
\hline Dunas/Areial & 1 & Ribeiro (2006) \\
\hline Floresta Nativa & 0,001 & $\begin{array}{l}\text { Paranhas Filho et } \\
\text { al. (2003) }\end{array}$ \\
\hline Manguezal & 0,0001 & Ribeiro (2006) \\
\hline Mata Ciliar & 0,016 & Silva et al. (2007) \\
\hline Pastagem & 0,055 & $\begin{array}{l}\text { Valle Júnior et al. } \\
\qquad(2010)\end{array}$ \\
\hline Povoados/Distritos/Sedes & 0 & $\begin{array}{c}\text { Paranhas Filho et } \\
\text { al. (2003) }\end{array}$ \\
\hline Restinga & 0,01 & Stein et al. (1987) \\
\hline
\end{tabular}

\section{RESULTADOS E DISCUSSÃO}

As informações geradas sobre cada um dos fatores que compõem a EUPS, com seus dados equivalentes são apresentadas individualmente, a partir do processamento dos dados levantados de fontes diversas e que resultam no cálculo estimado de perda de solo para cada um dos ambientes considerados do Baixo São Francisco Sergipano (BSF). 


\section{Fator R (Erosividade)}

O maior valor de erosividade (R) estimado foi apresentado pelo município de Pirambu, situado no litoral, com 7227.391 Mg.mm/ha.h.ano, que apresentou média de pluviosidade de $1455 \mathrm{~mm}$, mostrando que em situações de alta pluviosidade são registrados maiores valores de erosividade. Vale destacar que e o município de Pirambu apresenta regime hídrico caracterizado pela presença de Floresta Tropical subperenifolia. No município de Canindé do São Francisco, situado na região semi-árido minada por caatinga hiperxerófila, apresenta média anual de 457,81 mm de precipitação, apresentou o menor fator $\mathrm{R}$ entre as estações avaliadas com valor de 2704.61Mg.mm/ha.h.ano, demonstrando que baixos índices pluviométricos ocasionam baixos valores de $\mathrm{R}$.

A erosividade classificada como fraca representou $9,09 \%$, do total do BSF sergipano, moderada com $36,36 \%$ e moderada a forte com $54,54 \%$. Sabe-se que somente os dados de erosividade não são suficientes para diagnosticara vulnerabilidade de uma determinada área aos processos erosivos. Então, faz-se necessário uma análise de outros fatores de forma conjunta para melhor diagnostico da área.

Confrontando a localização espacial das estações e as isoietas com as médias históricas de precipitação no BSF, percebe-se que as isoietas com maiores valores foram as mais próximas ao litoral. A espacialização do fatorR, calculado a partir das isoietas, permitiu a identificação dos maiores valores de $\mathrm{R}$ na região da foz do Rio São Francisco, Município de Brejo Grande, onde predomina o ecossistema de restinga e os menores valores na região onde se encontram os municípios de Poço Redondo e Porto da Folha, caracterizados pela forte presença de caatinga hiperxerófila, em áreas caracterizadas como parte do sertão semiárido (Figura 2).

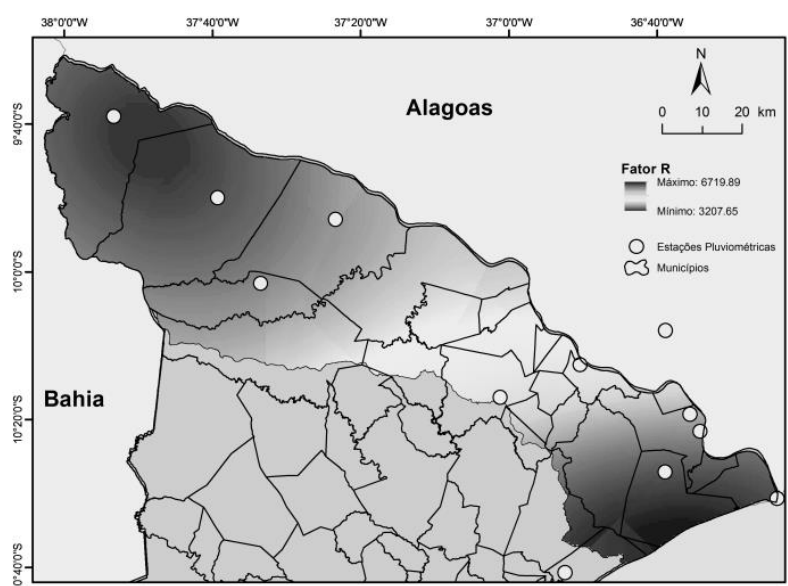

Figura 2 - Variação do fator R, utilizando o método da Krigagem (Geoestatística) no Baixo São Francisco sergipano.

\section{Fator K (Erodibilidade)}

Considerando que a erodibilidade se define como o efeito integrado de processos que regulam a chuva no momento que encontra o solo e a sua respectiva resistência no que tange a desagregação de partículas e consequentemente movimentos destas, indicando o grau de suscetibilidade a erosão em relação às propriedades inerentes ao solo (ARRAES et al., 2010), fez-se necessário a verificação das classes de solos dominantes na área para melhor instrução dessa variável. Vale destacar que foram identificadas 12 classes de solos no Baixo São Francisco, com predomínio do Neossolo Litólico, ocupando 30,7\% do BSF. No entanto, somados os percentuais das quatro classes de Neossolos (Flúvico, Litólico, Quartzarênico e Regolítico) obtêm-se 48,86\% de ocupação no BSF, seguido do Argissolo com 27,13\%. Com menor porcentagem ocorrem os solos indiscriminados de mangue que ocupam somente $0,6 \%$ do total do BSF, nas áreas restritas à região estuarina do Rio São Francisco (Figura 3).

Observou-se que há predominância de solos com fator de maior erodibilidade $(0,03$ a 0,045t.ha.h/ha.MJ.mm) associados a classe dos Neossolos, tanto Litólicos quanto Quartzarênicos e Regolíticos, que ocupam a maior parte da área do BSF. Os Neossolos Litólicos são solos rasos com menos de 20 cm de espessura, pois são solos em via de formação, ou com baixo grau de intemperismo.

Os solos indiscriminados de mangue são caracterizados como solos halomórficos muito pouco desenvolvidos escuros e com alto teor de sais provenientes da água do mar, formados em ambientes de mangues a partir de sedimentos flúvio-marinhos recentes misturados com detritos orgânicos, de natureza e granulometria variada (EMBRAPA, 2013), eles ocupam uma pequena parcela do Baixo São Francisco sergipano, porém estão inseridos na classe com maiores valores (> 0,06t.ha.h/ha.MJ.mm) ocupando $0,06 \%$ da área total do BSF, assim são classificados pela sua vulnerabilidade causada pela não ocorrência de agregação desses solos se apresentando bastante dispersos em face da sua reconhecida salinidade gerando carreamento de sedimentos.

Os Planossolos, que ocupam 9,92\% da Bacia, possuem $\mathrm{o}$ menor fator $\mathrm{K}$ com apenas 0,02025t.ha.h/ha.MJ.mm, essa classe de solo ocorre preferencialmente em áreas de relevo plano ou suave ondulado, sendo solos minerais imperfeitamente ou mal drenados. 


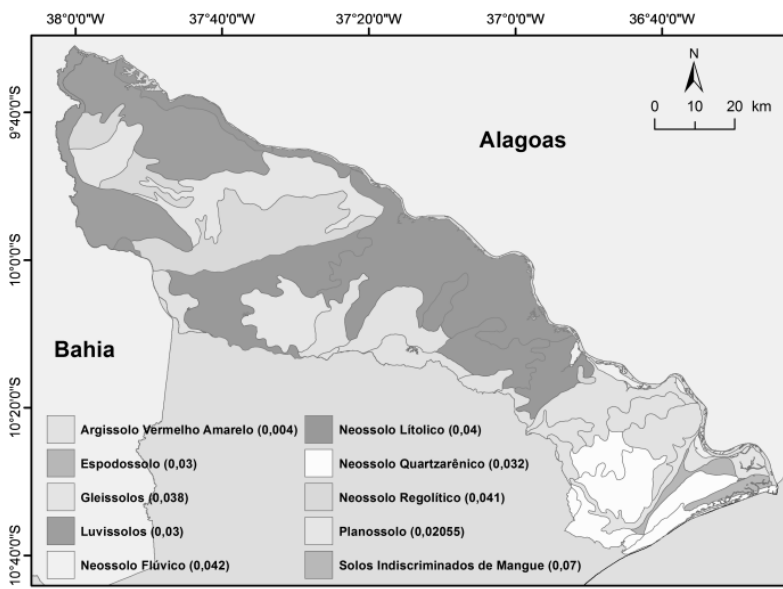

Figura3 - Classes de solos existentes no Baixo São Francisco sergipano e seus respectivos fatores $\mathrm{K}$.

\section{Fator LS (fator de Declividade e Comprimento da Rampa)}

A área do BSF sergipano possui a predominância do relevo classificado como plano com $60,48 \%$ da sua cobertura total (Figura 4), seguido do Suave ondulado com 33,62\% e, $0,18 \%$ com relevo Forte ondulado.

O fator LS exerce influência importante no processo erosivo, mas não sendo o principal agente causador da erosão no BSF. O grau de declive e o comprimento da encosta influenciam na velocidade de escoamento superficial, favorecendo a erosão em termos de tamanho e quantidade de material transportado (SILVA et al, 2015).

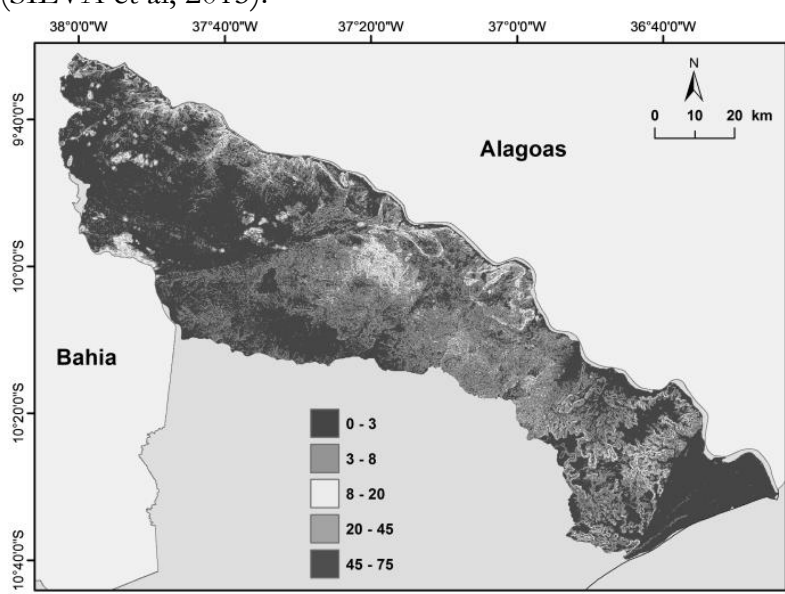

Figura 4 - Classificação das declividades (\%) no Baixo São Francisco sergipano.

Os valores de LS $(0,389$ a 0,932$)$ se concentram nas regiões onde o relevo possui maiores inclinações, e nas áreas onde foi classificado como relevo plano obtevese valores de LS entre 0 e 0,03304 (Figura 5).

Maiores declividadesassociadas com classes de solos com maior vulnerabilidade e maiores indices de pluviosidade potencializama ocorrência de eventos erosivos, causando elevado desprendimento de particulas de solo, onde observa-se maiores valores de LS. Quando se provoca uma relação como uso e ocupação do solo, constata-se que nessas áreas há presença de Floresta estacional ou Caatinga arbustiva. As pastagens estão inseridas em áreas com menores valores para o fator LS.

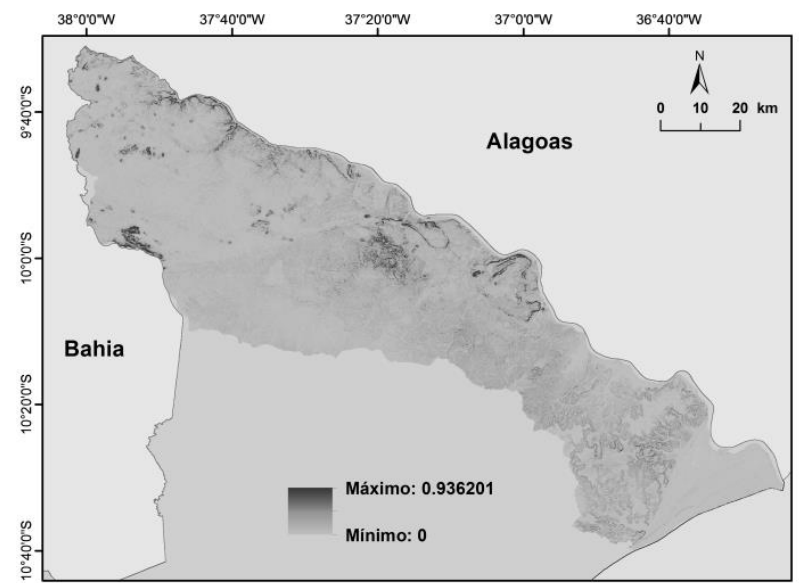

Figura5 - Distribuição fatorLS no Baixo São Francisco.

\section{Fator CP (fator de Práticas Conservacionistas)}

Em mapas do BSF sergipano são apresentados os seus usos e ocupações e o fator $\mathrm{CP}$, sendo que a maior parte dos valores calculados para este fator está inserida dentro da faixa que vai de 0,0549 a 0,098 . Quanto mais os valores se aproximarem de 1 , isto pode ser interpretado como pouco ou nenhum cuidado no manejo e conservação do solo.Vale destacar que embora não apresente uma relação direta com o fator $\mathrm{CP}$ as áreas com valores iguais a zero, sofrem também pouca influência das chuvas, como corpos d'água, e áreas construídas (Figuras 6 e 7$)$.

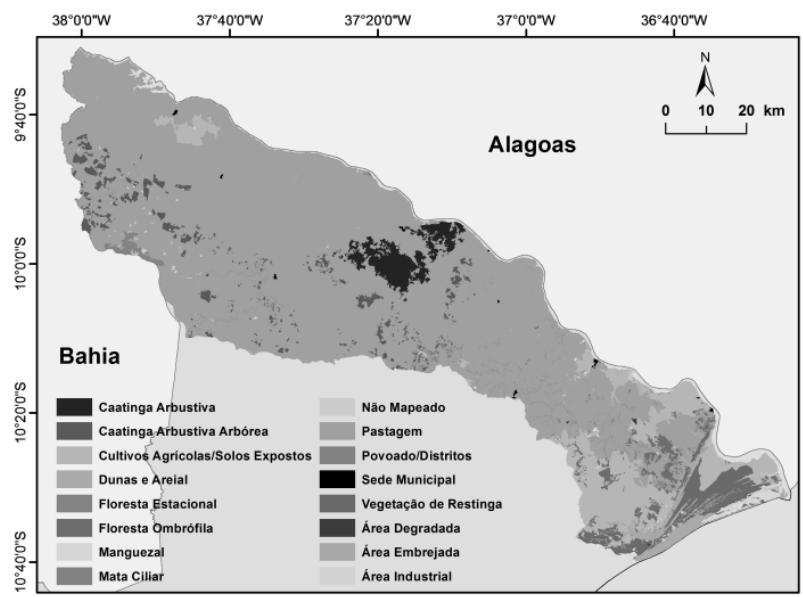

Figura6 - Uso e Ocupação do solo no Baixo São Francisco sergipano. 
As áreas onde foram identificados os maiores valores de CP estão associados a trechos com solos expostos, cultivos agrícolas e pastagens e os menores valores estão associados com as Florestas e Caatinga. Foi visto que é bastante expressivo o uso dos solos com as pastagens no BSF sergipano com valor de 0,055, abrangendo aproximadamente $76 \%$ da área.

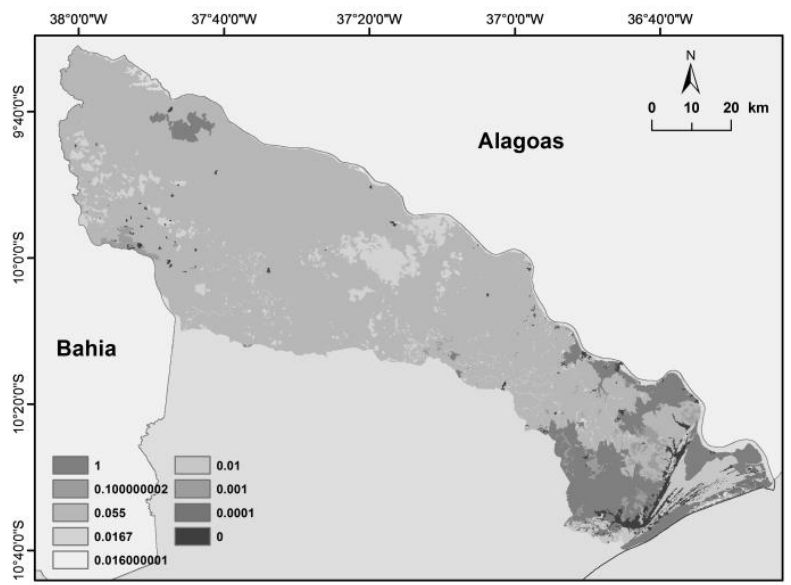

Figura 7 - Distribuição do fator CP no Baixo São Francisco sergipano.

Vale ratificar que o fator $\mathrm{CP}$ aqui vem avaliado tomando como passe o uso e ocupação do solo, uma vez que não foram identificadas praticas conservacionistas desde as mais simples como o cultivo em nível, plantio em contorno, cordões de vegetação permanente, ou mesmo terraceamento.

\section{A (Perda de solo)}

Quanto a perda de solo observou-se uma amplitude de dados que variou de 0 até 63,64 t/ ha.ano de estimativa de perda de solo (Figura 8). Em 67,17\% da área estudada os menores valores de perda do solo variaram de 0 a $0,75 \mathrm{t} / \mathrm{ha}$.ano, e os maiores valores encontrados (44,67 a 63,64 t/ha.ano) abrangem uma área de aproximadamente $0,17 \%$ do BSF sergipano.Áreas degradadas, solos expostos e áreas com maiores comprimentos de rampa e declividades estão associados as maiores perdas de solo corroborando com dados encontrados por Valladares (2012).

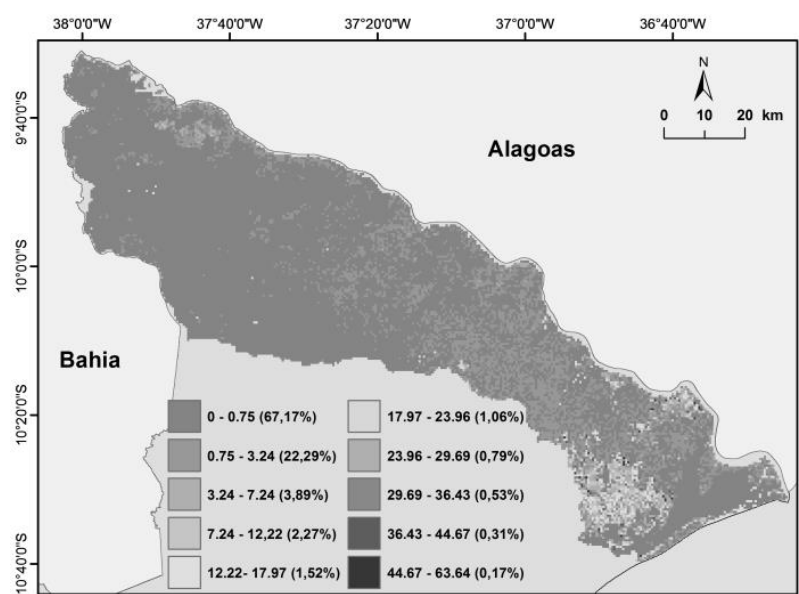

Figura 8 - Distribuição da estimativa de perda de solo (t/ha.ano).

Nas áreas de pastagem,predominantes no BSF, foram encontrados valores que variaram de 0 a 0,75t/ha.ano. Os dados nulos (fator $\mathrm{A}=0 \mathrm{t} / \mathrm{ha}$.ano) estão associadosa corpos d'água ou áreas não mapeadas onde atribui-se o valor zero ao fator CP.

A predominância de áreas com menores perdas de solo, como mostrado na Figura 8 se justifica em parte, pela predominância de áreas com ocorrência de baixa erosividade, associada à uma maior cobertura do solo como as pastagens, onde Gurgel et. al. (2011) encontraram valores semelhantes em seu trabalho no município de Riachão das neves - BA.

Uma consequência marcante nas mudanças no uso do solo advémda ocupação antrópica, principalmente com atividades agrícolas. Silvaet. al. (2007), encontraram índices de perdas médias de solopara áreas de mata nativa de $0,39 \mathrm{t} /$ ha.ano e após a mudança no uso para pastagem foi refeito o calculo de perda de solo, onde foi encontrado o valor de $3,86 \mathrm{t} / \mathrm{ha}$.ano.

Ademais, os possíveis efeitos de um manejo intensivo das terras na vulnerabilidade à erosão, também não são tão notados uma vez que também não são muito grandes as áreas destinadas à produção de grãos no BSF, quando a mecanização promove mais fortemente a desestruturação dos solos.

\section{CONCLUSÕES}

Os dados demonstram perda de solo pouco expressivas em todo o BSF, ás vezes creditado às baixas pluviosidades, outras aos declives não fortes, ou até mesmo a associação desses fatores com a uso e ocupação do solo, mesmo em cultivos agrícolas, geralmente realizados de formas menos intensas.

A baixa expressividade das perdas de solo se mostra resultante da combinação de vários fatores, com ênfase na baixa erosividade considerada fraca em quase $50 \%$ de toda área, bastante associada à uma maior cobertura do solo com pastagens. 
A maior erodibilidade se mostrou mais expressiva nas áreas dominadas por Neossolos (Litólicos, Quartzarênicos ou Regoliticos), com ênfase aos Neossolos litólicos que ocupam expressivas faixas do ecossistema Caatinga.

A utilização da EUPS se mostrou viável na avaliação da susceptibilidade às perdas de solo, permitindo uma avaliação da contribuição individual de cada fator considerado na equação.

\section{REFERÊNCIAS}

AGUIAR NETTO, A. O.; COSTA, P. R. S. M. ; OLIVEIRA, H. U. . Knowledge and power in the São Francisco river basin committee. Revista Tempos $e$ Espaços em Educação, v. 9, p. 25-38, 2016.

ANA/GEF/PNUMA/OEA, ANA - Agência Nacional de Águas; GEF - Fundo Mundial para o Meio Ambiente; PNUMA - Programa das Nações Unidas para o Meio Ambiente; OEA - Organização dos Estados Americanos. Plano de Recursos Hídricos da Bacia Hidrográfica do Rio São Francisco para 2016 - 2025: Diagnóstico da Dimensão Técnica e Institucional. RP1A. Volume 2 - Caracterização da Bacia Hidrográfica - $2^{a}$ parte, Revi. Salvador, 2015.

ARRAES, C.L.; BUENO, C.R.P.; PISSARRA, T,C.T. Estimativa da erodibilidade do solo para fins Conservacionistas na microbacia córrego do Tijuco, SP. BioscienceJournal, v. 26, n. 6, p. 849-857, 2010.

ARAÚJO FILHO, R. N.; HOLANDA, F. S. R.; ANDRADE, K. R.. Implantação de técnicas de bioengenharia de solos no controle da erosão no baixo São Francisco, estado de Sergipe. Scientia plena. v. 9, n. 7, 2013.

BAPTISTA, G.M.M.. Diagnóstico ambiental da Perda Laminar de solos por meio do geoprocessamento. Dissertação de Mestrado. Departamento de Engenharia Civil, Universidade de Brasília, p.112, 1997.

BERTONI,J.; LOMBARDI NETO, F. Conservação do Solo. São Paulo: Editor Ícone, 1990, p.335

BORGES, K. M. R.; CARVALHO JÚNIOR, O. A.; MARTINS, E. S.; GOMES, R. A. T.; GUIMARÃES, R. F. Vulnerabilidade natural: a perda de solo da bacia do rio Carinhanha (MG/BA) usando uma abordagem qualitativa da equação universal de perda de solos. Geographia, v. 14, n. 27, p. 101-125, 2013.

CARVALHO, N. O. Hidrossedimentologia Prática. $2^{\text {a }}$ ed. rev. e ampliada, Rio de Janeiro: Interciência, 2008.
COMITÊ DA BACIA HIDROGRÁFICA DO SÃO FRANCISCO - CBHSF. A bacia bidrográfica do São Francisco.Disponível em

$<$ www.saofrancisco.cbh.gov.br> . Acesso em $22 \mathrm{dez}$ 2016.

CODEVASF - Companhia de Desenvolvimento dos Vales do São Francisco e do Parnaíba. Mapeamento temático de uso da terra no Baixo São Francisco. Brasília/DF, 2002.

CPRM, Serviço Geológico do Brasil. Geobank. 2003. Disponível em: <http://geobank.cprm.gov.br>. Acesso em 17 mai 2015.

EMBRAPA, Sistema brasileiro de classificação de solos.Centro Nacional de Pesquisa de Solos.Rio de Janeiro,2013. p.306.

FAIRFIELD, J.; LEYMARIE, P. Drainage networks from grid digital elevation models. Water Resources Research, v.27, n.5, p.709-717, 1991.

FARINASSO, M.; CARVALHO JÚNIOR, O. A.; GUIMARÃES, R. F.; GOMES, R. A. T.; RAMOS, V. M. Avaliação qualitativa do potencial de erosão laminar em grandes áreas por meio da Eups utilizando novas metodologias em sig para os cálculos dos seus fatores na região do Alto Parnaíba-Pi-MA. Revista Brasileira de Geomorfologia, n.2, p.73-85, 2006.

GUERRA, A. J. T.; FULLEN, M. A.; JORGE, M. C. O. ; BEZERRA, J. F. R. ; SHOKR, M. S. Slope Processes, Mass Movement and Soil Erosion: A Review. Pedosphere, v. 27, p. 27-41, 2017.

GURGEL, R. S., CARVALHO JUNIOR O. A., GOMES R. A. T., GUIMARÃES R. F., CÂMARA J. F. A., ARAÚJO SOBRINHO D., MARTINS E. S., BRAGA A. R. S. Identificação das áreas vulneráveis à erosão a partir doemprego da EUPS - equação universal de perdas de solos nomunicípio de Riachão das Neves BA. Geografia Ensino \& Pesquisa, v . 15, n.3, 2011

GUERRA, A. J. T. Processos erosivos nas encostas. In: GUERRA, AntônioJose Teixeira. CUNHA, Sandra Baptista da. (org.) Geomorfologia uma atualização de bases e conceitos.10 ed. Rio de Janeiro: Bertrand Brasil, 1994.

INDE - Infraestrutura Nacional de Dados Espaciais. Portal do INDE. Disponível em: $<$ http://visualizador.inde.gov.br>. Acesso em 11 abr. 2014. 
ISSA, L. K.; RAISSOUNI, A.; MOUSSADEK, R.; ARRIM, A. EL. Mapping and Assessment of Water Erosion in the Khmiss Watershed(North Western Rif, Morocco), Journal of Current Advances in Environmental Sciences, v. 2, n. 4, p. 119-130, 2014.

KUMAR, A.; DEVI, M.; DESHMUKH, B. Integrated remote sensing and geographic information system based RUSLE modelling for estimation of soil loss in western Himalaya, India. Water resources management, v. 28, n. 10, p. 3307-3317, 2014.

MAGYARI-SÁSKA, Z. HAIDU, I. Study on soil erosion in the Upper Mureş Basin.GeographiaTechnica, v. 2, 61-67, 2008.

MANNIGEL, A. R.; CARVALHO, M. D. P. E.; MORETI, D.; MEDEIROS, L. D. R. Fator erodibilidade e tolerância de perda dos solos do Estado de São Paulo. Acta Scientiarum, v. 24, n. 1, p. 1335-1340, 2002.

MOORE, I. D.;WILSON, J. P. Length slope factor for the Revised Universal Soil Loss equation: simplified method of solution. Soil Water Conservation Society, v. 47, n. 5, 423-428, 1992.

PARANHOS FILHO, A.C.; FIORI, A. P.; DISPERATI L.; LUCCHESI, C.; CIALI, A.; LASTÓRIA, G. Avaliação multitemporal das perdas de solos na bacia do rio Taquarizinho-MS. Paranaense Bull Geosciences. v. 52, p. 49-59, 2003.

PIMENTA, M. T. Caracterização da erodibilidade dos solos a sul do rio Tejo. p. 18, 1998.

RIBEIRO, L. S. Quantificação de perda de solo por erosão no município de Campos dos Goytacazes/RJ através de técnicas de geoprocessamento. (Dissertação de mestrado), Universidade Estadual do Norte Fluminense Darcy, Campos dos Goytacazes - RJ. Fevereiro - 2006.

SANTOS, J.C.N.; ANDRADE, E.M.; MEDEIROS, P.H.A.; NETO, J.R.A.; PALÁCIO, H.A.Q.; RODRIGUES, R.N. Determinação do fator de cobertura e dos coeficientes da MUSLE em microbacias no semiárido brasileiro. Revista Brasileira de Engenharia Agrícola e Ambiental, v.18, n.11, p. 1157-1164, 2014.

SEPLAN, Secretaria de Estado do Planejamento. Plano de DesenvolvimentoTerritorial Participativo de Sergipe (PDTP). Disponivel em:

<http://www.se.gov.br/userfiles/arquivos/192/cadern O_especial_1_etapa_e_mapa_territrios.pdf $>$ Acesso em 10nov. 2015.
SERGIPE (Estado). Superintendência de Recursos Hídricos. Atlas Digital sobre Recursos Hidricos de Sergipe. Aracaju: SENPLANTEC, 2012. CD-ROM.

SUDENE - Superintendência do Desenvolvimento do Nordeste. Mapa de erosividade do Nordeste. Recife: SUDENE, 1985, 50 p.

SEPLAN - Secretaria de Estado do Planejamento de Sergipe. Mapa territórios sergipanos. Aracaju: GIGEC/SUPES/SEPLAN, 2007.

SILVA, A. M.; HUANG, C.H. ; FRANCESCONI, W. ; SAINTIL, T.; VILLEGAS, J. . Using landscape metrics to analyze micro scale soil erosion processes. Ecological Indicators, v. 56, p. 184-193, 2015.

SILVA, A. M.; SCHULZ, H. E.; CAMARGO, P. B. Erosão e hidrossedimentologia em bacias hidrográficas. São Carlos: Rima, 2007. 153p.

SILVA, V. C. DA. Estimativa da erosão atual da bacia do Rio Paracatu (MG/GO/DF). Pesquisa Agropecuária Tropical, v. 34, n. 3, p. 147-159, 2004. Disponível em: <http://www.revistas.ufg.br/index.php/pat/article/vie wArticle/2308>. Acesso em 22 Jan. 2015.

STEIN,D.P.; $\quad$ DONZELLI,P.L.; GIMENEZ,A.F.; PONCANO,W.L.; LOMBARDI NETO,F. Potencial de erosão laminar, natural e antrópico, na Bacia do PeixeParanapanema. Anais $4^{\circ}$ Simpósio Nacional de Controle de Erosão. Marília-SP: ABGE / DAEE, p.105-135, $1987 .$.

SUDENE (Superintendência do Desenvolvimento do Nordeste). Mapa de erosividade do Nordeste. Recife: SUDENE, p. 50, 1985.

USGS - U.S. Geological Survey <http:// // earthexplorer.usgs.gov/fgdc/3373>Acesso em 10 out. 2014.

VALLADARES, G. S.; GOMES, A. D. S.; TORRESAN, F. E.; RODRIGUES, C. A. G.; GREGO, C. R. Modelo multicritério aditivo na geração de mapas de suscetibilidade à erosão em área rural. Pesquisa Agropecuaria Brasileira, v. 47, n. 1, p. 1376-1383, 2012.

VALLE JÚNIOR, R. F. DO; GALBIATTI, J. A.; MARTINS FILHO, M. V.; PISSARRA, T. C. T. Potencial de erosão da bacia do Rio Uberaba. Engenharia Agrícola, v. 30, p. 897-908, 2010.

VIECELI, N.; BORTOLIN, T. A.; MENDES, L. A.; BACARIM, G.; CEMIN, G.; SCHNEIDER, V. E.. Morphometric evaluation of watersheds in Caxias do Sul City, Brazil, using SRTM (DEM) data and 
GIS. Environmental Earth Sciences, v. 73, n.9, 5677-5685, 2015.

WISCHMEIER, W. H.; SMITH, D. D. Predicting rainfall erosion losses: a guide to conservation planning.Washington, DC: USDA, 1978. (Agriculture handbook, 537). 